\title{
Perceptions of Vanuatu seasonal workers on conducting oral health promotion in their community
}

Cath Conn, Losi Sa’uLilo, Daniel Fernández, Kaisa Wilson

\begin{abstract}
Introduction: Poor oral health is a significant public health problem in Vanuatu, and in Melanesia more generally. It has a negative impact on overall health and well-being and is linked to heart disease and diabetes. Determinants of health such as poverty, poor diet, geographical remoteness, and limited oral health care are some of the contributing factors of poor oral health in Vanuatu. Vanuatu seasonal workers visit Aotearoa New Zealand annually under the Recognised Seasonal Employer (RSE) Scheme, for the purposes of fruit processing. Fruit of the Pacific (FOP), a charitable trust, has collaborated with Oral Health at Auckland University of Technology (AUT) to provide oral health care to seasonal workers since 2010. Emerging from these relationships, a community-led initiative was undertaken by returning workers to Vanuatu in collaboration with FOP involving good oral health, especially tooth-brushing.
\end{abstract}

Method: In 2016, a small-scale study was undertaken of the perceptions of Vanuatu seasonal workers of oral health promotion in their community. An exploratory focus group discussion with seasonal workers and a contextual review of sources was undertaken. This paper discusses oral health in Vanuatu and presents the findings of the study.

Results/Discussion: The seasonal workers are well aware of the poor oral health of their communities, describing important gains from community-led sharing of oral health messages, including cultural knowledge, empathy, and appropriate forms of communication. They noted that stakeholders and funders are needed on an ongoing basis to support such mechanisms.

Conclusion: The study presents and discusses a positive case of Pacific community leaders from migrant diaspora taking action on oral health. This can inform similar actions in Vanuatu, Melanesia, and other Pacific island communities. Further research would be valuable to explore community oral health messaging in Vanuatu and in other settings. Given the potential of the 'digital dividend' for greater access to the internet in future, ehealth promotion tools alongside appropriate community programming, might provide a low cost and sustainable model of Pacific oral health promotion.

Keywords: Recognised Seasonal Employer (RSE) Scheme, community-led oral health promotion, Vanuatu migrant workers; Pacific oral health promotion.

The research team is based at AUT School of Public Health \& Psychosocial Studies and AUT School of Clinical Sciences - Oral Health Department. For correspondence: cath.conn@aut.ac.nz 


\section{Introduction}

\section{Oral health in Vanuatu}

Poor oral health is a significant problem in Vanuatu: it has a negative impact on overall health and well-being and is linked to non-communicable diseases such as heart disease and diabetes. It not only contributes to morbidity and mortality, but it can affect the ability to eat, speak, smile and socialise due to pain or social embarrassment (Underwood, Birdsall, \& Kay, 2015). Determinants of health such as poverty, geographical remoteness, increased eating of processed foods, and limited health care contribute to this serious public health problem (World Health Organisation, 2007).

More than $80 \%$ of people in Vanuatu live in rural communities spread over 85 separate islands, with six dentists and 17 dental professionals for an estimated population of 282,814 (Central Intelligence Agency, 2018) (i.e. a ratio of 1: $34,000)$. Official statistics about the population's dental caries status, as in most Pacific Island nations, are very limited, adding to the challenge of targeting services, and seeking support for oral health care (Doherty, Blinkhorn, \& Vane, 2010). A review of the oral health of Pacific Islands (including Vanuatu), based on 1974 data, noted that urban communities, such as Port Vila (the capital of Vanuatu) and Santo experienced a 'decayed, missing, and filled teeth' (DMFT) score of 3.32 for adults and 2.43 for 12-year-old children. Aoba and Ambryn, as rural communities, had 0.88 and 0.17 DMFT scores respectively (Doherty et al., 2010). Yet, in 2003 WHO estimated a high DMFT score of 4.4 for children under 12 years in Melanesia (which includes Vanuatu), and up to 13.9 DMFT score for adults (World Health Organisation, 2003). This decline in oral health status demonstrates the seriousness of the issue, with Melanesia among the worst affected.

In addition to social and physical environmental factors playing an important role in oral disease, lack of oral health professionals contributes to the problem (Aldenhoven, 2015), with particularly poor access for remote communities resulting in limited and inadequate care and long waiting times (Papatheodorakis \& Righetto, n.d.). Access to oral health care in rural areas is often provided by unqualified or non-trained health workers (Steel, 2013). In addition, the high cost of private dentistry is a barrier to good oral health, and is only available in urban centres (Aldenhoven, 2015).

Inadequate access between islands by irregular shipping and poor road networks within the islands, enhances isolation and makes the cost of providing health care in general very high (Livtunvanu, 2011), exacerbated by the high cost of dental facilities, equipment and materials. Migration to urban areas has also contributed to poor oral health, given the effects of overcrowding and poor living conditions, such as lack of sanitation, poor nutrition, and increased addictions (World Health Organisation, 2012).

In 1979 WHO set a target of 3 DMFT for children at age 12 years which remains in place (World Health Organisation, 2003). Oral health promotion seeks to achieve sustainable improvements in oral health and reduce inequities through action directed at the underlying determinants of oral health (Schou \& Locker, 1997). To manage and prevent poor oral health, the Ministry of Health in Vanuatu in conjunction with non-government organisations, have allocated funding to improve health care services, to develop the skill set of health professionals, and to increase resources including dental equipment, as well as supporting small-scale community health initiatives. These have been designed to support and empower communities within rural and urban areas, to educate young children, as young as five years of age, to older adults, aged over 65 years,

Pacific Health, vol 2, 2019 ISSN 2537-8864 
to use oral health resources, to reduce the rate at which oral health problems are occurring. The programmes available include but are not limited to 'Shining Smiles on Efate Island' which seeks to promote oral health among school children between the ages of five and ten, and the Vanuatu Dental Association, 'Happy baby smiles of the South Pacific' (World Dental Association, 2017). The Health Department and the Presbyterian Church of Vanuatu have initiated oral health promotion to primary schools (Willie, 2017).

In addition, Fruit of the Pacific (FOP), a New Zealand based charitable trust, supports oral health education in communities, and provides the means to train seasonal workers to become oral health promoters (Steel, 2013).

\section{Vanuatu Oral Health Awareness (VOHA) Programme}

FOP supports Pacific communities by partnering with seasonal workers who travel to work in Aotearoa New Zealand for three to six months of each year under a government labour policy; the Recognised Seasonal Employer (RSE) scheme (Steel, n.d.). The oral health programme, known as Vanuatu Oral Health Awareness (VOHA) started in 2010, and was designed to assist with good oral health practice. The programme collaboratively works with established national and international organisations and funders including Colgate, Marine Reach, the Butterfly Trust, The Presbyterian Church of Vanuatu and World Vision. In 2016, the VOHA reached over 15,000 children and adults with the intention of promoting good oral health practice (Steel, n.d.).

Since 2010, the Auckland University of Technology (AUT) School of Clinical Studies - Oral Health Department has provided dental treatment and education to seasonal workers. Between 25 to 30 seasonal workers travel from Te Puke to the University once a year as part of the oral health programme to receive dental care. Dental hygiene care is provided by final year students, with the more complex dental procedures, such as fillings and extractions, provided by dentists. Students, of the Bachelor of Oral Health, provide care under the supervision of qualified registered dental practitioners such as dental hygienists, oral health therapists, dentists and dental specialists. Apart from oral health care, students also provide information and advice to the seasonal workers such as brushing and flossing techniques; also they provide information on diet and the effects of sugary food on teeth. This mirrors services provided to the community by AUT Oral Health at their Akoranga clinic. At the completion of their treatment, the seasonal workers are given dental products to continue with their care such as toothbrushes, dental floss, toothpastes, mouthwashes and pamphlets with information about dental care. The visiting programme has been reviewed by the Oral Health Department and there are plans to increase the visits to twice a year starting from 2019.

From its inception, seasonal workers appreciated VOHA to the extent that they asked for the production of a tangible resource to take back to Vanuatu to inform their families and the wider communities about oral health care. FOP assisted in the making of a DVD in the local language (Bislama), 'Yu Me Gat Wan Big Fella Smile', which highlighted the causes of tooth decay and gum disease and the importance of regular teeth cleaning. The following year they made further requests for more resources, information and training in the skills of oral health promotion.

\section{Methods}

In 2016, a small scale study was undertaken of the perceptions of Vanuatu seasonal workers on conducting oral health promotion in their community. An 
exploratory focus group discussion was conducted with seasonal workers in Te Puke, some of whom had been involved in the programme, and a contextual review of sources was carried out. Ethics approval was granted by Auckland University of Technology Ethics Committee (AUTEC 15/293 'Pacific recognised seasonal employers workers' experiences of an oral health programme in New Zealand'). Data collection and analysis took place in Te Puke and Auckland in 2016 and 2017. The focus group was facilitated by an experienced community health researcher from AUT, and it was conducted in English. Audio recording was used to record the focus group, and thematic analysis was used to identify the main issues following Braun and Clarke (2006). Eight seasonal workers, recruited through FOP, took part in the focus group discussion; some were from Port Vila the capital and some were from other locations in Vanuatu, with one participant from Papua New Guinea. Both men and women took part. At least one participant had been involved in VOHA since 2010; others more recently. The field researcher provided a summary of main points to the group for their comments and verification.

\section{Results and Discussion}

The seasonal workers are well aware of the poor oral health of their communities; they described gains from community-led sharing of oral health messages; and they also described the lack of resources and the role of stakeholders and funders in ongoing support for oral health promotion.

\section{Seasonal workers are aware of the poor oral health of their communities}

The seasonal workers described the extent of the oral health problem, referring to the challenges as well as needs,

Oral health is a big problem in Vanuatu... they are facing problems with their teeth like tooth decay and health and hygiene like some people don't brush their teeth even though they know, they are lazy to teach their teeth, cleanliness around the house something like that.

We have 83 islands in Vanuatu and some of the outer islands they never know have never heard how to brush their teeth.

When we go to villages we ask the kids because we have a chat, how often do they clean their teeth and a lot of kids say they don't brush their teeth.

At the moment Vanuatu is facing a big problem with tooth decay so I am thinking the best thing is more and more awareness to the villages to reduce the problems.

The seasonal workers also highlight the issue of poor access to services,

Thank you, I had a problem with my teeth, for one week so when I went to the hospital to the dentist to take it out, but the dentist wasn't there, he was from the other part of the island and the hospital is in the area that we live but he wasn't there so they just gave me panadol to take the pain from my, but nothing happened so when I finished the panadol I went back to the hospital but the dentist wasn't there. So just came home and tried my own to pull it out.

Lack of transportation and remoteness is also discussed,

Some of them they travel very far to come to Vila. All the dentists stay in Vila - 2-3 in Vila, and then 1-2 in Santo then Malekula but the other 83 
islands, there is no dentist so they have to travel to come by boat or island to come to a bigger island and then take plane to come fly to Vila.

It seems that the increased knowledge, awareness, and concern for their communities' health, is a strong motivator for seasonal workers involvement in the programme, volunteering time and effort for the messaging.

\section{The role of Vanuatu seasonal workers as leaders in oral health}

The seasonal workers expressed feelings of empowerment as oral health champions and community leaders, making positive changes within their respective communities, whether at their local school or church. They acknowledged the various strategies they use - such as cultural sensitivity and appropriate forms of communication, good interpersonal skills, and they stress the importance of physical materials, such as the information DVD, free toothbrushes, and other aides. They compared this approach to the less successful methods of non-Vanuatu people,

Easy. Cause we went back and teach in our language rather than like some of you people that come and teach and people don't understand. Like VOHA we go back and find [what] works well. [Organisations in oral health] use us for translation and one other thing, when other people are coming they are shy to talk but its better with us.

When we went to Mele school, there is two guys from [NGO] - one is dentist - one lady, one young man from Australian and they run their programme first and then after that they took about 5 min and then after they finish they ask me and $\mathrm{K}$ to go and we talk about our programme that we learn here from you guys and the lady asked $\mathrm{K}$ - where did you go to university to learn that? And I was surprised and asked her again and she said where did you go to learn your programme, university or what, because she said your programme is really good.

They also acknowledged the value in receiving community health training,

I remember in 2010 we start with training with Dr B and then some training to teach our people in our community and then we went back to our country and went round the communities and went to the schools and teach them how to brush; giving them toothbrush and it worked very well because we are teaching - some role plays, even we went to MoE and they said it's a really good programme and they said we have to do because it's a real need in Vanuatu and it's a good programme to teach in schools and even in communities.

They acknowledged that they did this voluntarily and in their own time, but that resources are important,

Yes the first year we do - no pay - first, second, third - no pay. Fourth (FOP) found a little funding to help us - but we come here and its our heart when we come here to teach our community and volunteer to do this.

We have a poster but its too small.

They need a projector to make small presentation. We have a DVD that we use - K's husband made it so when we go to the villages / churches we show it.

When asked about what was motivating the community they noted that making it interesting, and the provision of toothbrushes was important, 
They are interested because when we give out the message we give out the brushes as well.

When we start in 2013 - we took bamboo toothbrush - before last year we start taking from Fiji from Dr N and now we get every toothbrush from Colgate Fiji but 15,000 last year, and before that $10,000 \ldots . .$. and with $\mathrm{MoH}$ and I go by myself and store it myself and we work together with [NGOs] when we go to the island with them I give them toothbrush to take, so it makes like we will go everywhere and give them toothbrushes.

When we go to the hospital you will see a long line of people facing problems with their teeth. People are starting to realise teeth are very important to look after, so when we go to the villages they are really interested to listen.

When we go to the kids we make a role play and DVD - we never talk because they will not understand. And show posters - and role plays with kumara [sweet potato]. The other thing is when we go to each island we have to know what their culture is. Like on Tanna they chew kava, so when we go there we cannot say kava is no good, because it's their culture, we just say if you chew kava you must clean your teeth.

We illustrate to the kids like we take coconut food - like we make an illustration that your teeth looks like this. If a rat comes (like a bacteria) -We talk about kumara - if you plant it and don't look after your garden the rat will come and eat the kumara and cause rot.

$\mathrm{X}$ is our main man because he is a good example for them - because he has broken teeth and then he shows them, he puts lollies around his neck and he's the lolly man.

When asked what they liked best about the programme the various responses were,

The best thing is it works really well, the end of the day well I pass through and I see the kids start to brush their teeth.

When we go to the villages and our main target is the mothers from the villages, so we talk to them [as] our priority.

Because they stay in the house and look after the kids.

All the fathers every evening they go the nakamal [meeting place] they have not time to talk to the kids, but our main targets are the mothers, sometimes both, but mostly the mothers.

When asked what they might change there was concern for the need to repeat and reinforce messages,

I see when we go around the islands most of the people want to come and listen to the awareness so we say we will come around again.

We need to go two or three times.

Because sometimes when we go to the island we travel from one village to another village - so travel to the villages that have roads but sometimes miss villages that don't have access.

However, they note the barrier of lack of resources to do this, 
We need money for travelling because some of the place we have to pay and the road, for us to walk its ok but because we take toothbrushes etc. it's too heavy for us or if there is no road we pay people to help us carry.

That's the main problem we need to have our own transport, we need to have our own boat.

Brown (1994) reviewed 57 different studies evaluating the effectiveness of interventions to alter individuals' behaviour related to dental health. Results showed improvements in objective measures of dental health behaviours and actual oral health measures but interventions had only limited success in changing attitudes towards dental issues and achieved only short-term gains in knowledge. This issue of short-term gains, and the need for regular reminders, is referred to by the seasonal workers. However, on the plus side, when delivering the programme within local schools, at their local churches and teaching their family members about how to clean teeth and maintain good oral health, the seasonal workers observed that people within their local community were brushing their teeth, enjoyed learning about cleaning teeth twice a day, and were happy with their services. Oral health promotion workers noted that this made them more motivated and empowered to continue their services and that the community members receiving the information felt empowered to continue to do so.

\section{The role of stakeholders and funders}

Whilst the community led nature of this initiative was vital for successful messaging, and for spreading messages to different communities, external stakeholders and funders were important given that they provided much needed oral health materials and training and transport costs. As presented above, the seasonal workers refer to the importance of materials such as the toothbrushes, and teaching aides, and for contributions to the high cost of transport. However, they also stressed the need for repeated actions, and although this is a relatively low-cost programme, it relies on voluntary efforts along with ongoing resources; in an environment of poverty this brings into question the sustainability of the initiative. 


\section{Conclusion}

The study contributes to knowledge of Pacific community-based oral health promotion and the role of migrant diaspora in improving oral health. It presents and discusses a case of Pacific community leaders taking action, supported by key stakeholders in dental health, one that can inform similar actions. Sustained funding and other support for this programme and for oral health more generally, including for oral health research, are challenging obstacles. Nevertheless, this initiative seems to provide a promising platform as an empowerment method to continue good oral health practice, to benefit the health of the Ni-Vanuatu community.

From this small-scale study, it is clear that further research would be beneficial. The scale of the problem of oral health in Vanuatu and Melanesia is considerable and therefore merits attention. There is value in comparing these findings with experiences from other Pacific communities. Further, it would be valuable to undertake further research to explore the effectiveness of this initiative on ongoing dental health practices in Vanuatu communities, following a model of prototyping and change within oral health promotion programmes. Research also needs to incorporate appropriate Pacific action epistemologies, to study what works within different Pacific contexts (Conn et al., 2016).

Recommendations for the future include greater and continued support for community-led initiatives, especially taking advantage of diaspora communities in the Pacific, such as seasonal workers, who move back and forth between their overseas work location and home on a regular basis, and therefore are valuable conduits for knowledge and ideas (Watt et al., 2006; Aldwell et al., 2018).

\section{The 'Digital Dividend' and oral health in the Pacific}

Looking to the near and long-term future, the growing 'digital dividend' (World Bank, 2016) might offer significant and increased opportunities provided by greater access to the Internet and mobiles, for messaging and advocacy including tooth brushing and other aspects of oral health (Conn et al., 2017). Apps, games and videos are all relatively cheap to produce, and there is tremendous scope to develop these in local languages, using cultural norms, multimedia, and local means of communication attractive to populations; and there is a growing realisation of the potential of a co-design approach (Conn et al., 2017). In 2017, the Internet World Statistics reported that 82,764 people in Vanuatu used the internet. That is, $29.3 \%$ of the population of Vanuatu has access to information through the Internet (Internet World Stats, 2018). Kacific, a Vanuatu registered broadband satellite company is promising affordable and high-speed internet for all islands of Vanuatu in 2019, once its satellite, Kacific -1 is in orbit and fully operational. Currently, Kacific supplies direct internet connection through an old satellite for the Vanuatu Inter-Island Telemedicine and Learning Network (VITAL), connecting village health workers and rural nurses working in isolation to specialists and resources in Vanuatu's main centres. The new internet connectivity will improve access to information for education, health care, tourism, economic development, emergency response, disaster recovery, aid and access to government services (Willie, 2017). These are exciting developments, which may in future provide low-cost and sustainable means, within appropriate contextualised and community-led programming, for a Pacific model of oral health/ehealth promotion. 
Acknowledgements: Funding for this project was provided by the Auckland University of Technology in New Zealand. We would also like to thank Kylie Orr from Fruit of the Pacific for her invaluable support to this research.

\section{References}

Aldenhoven, M. (2015) Volunteering in Vanuatu. Retrieved from claredental.com/volunteering-in-vanuatu/

Aldwell, K., Caillud, C., Galy, O., Frayon, S., \& Allman-Farinelli, M. (2018). Tackling the consumption of high sugar products among children and adolescents in the Pacific Islands: Implication for future research. Health Care, 6(3), 2 - 11. doi: 10.3390/healthcare6030081

Braun, V., \& Clarke, V. (2006). Using thematic analysis in psychology. Qualitative Research in Psychology, 3, 77 - 101 . doi: 10.1191/1478088706qp063oa

Brown, L. (1994). Research in dental health education and health promotion: a review of the literature. Health Education Quarterly, 21(1), 83-102.

Central Intelligence Agency. (2018). The world factbook: Vanuatu. Retrieved from https://www.cia.gov/library

Conn, C., Nayar, S., Lubis, D., Maibvisira, C., \& Modderman, K. (2017). Vulnerable youth as prosumers in HIV prevention: Studies using participatory action research. Journal of Medical Internet Research: Public Health Surveillance, 3(3), e53.

Conn, C., Said, A., Sa'uLilo, L., Fairbairn-Dunlop, P., Antonczak, L., Andajani, S., \& Blake, G. O. (2016). Pacific Talanoa and participatory action research: Providing a space for Auckland your leaders to contest inequalities. The Research for Development Impact Network iii. Reflecting on evidence and practice in an age of inequality, 77, $49-53$.

Doherty, A., Blinkhorn, S., \& Vane, S. (2010). Oral health in the Pacific Islands. International Dental Journal, 60(2), 122-128. doi: 10.1922/IDJ_2242

Internet World Stats. (2018). Vanuatu: Internet usage, broadband and telecommunications reports. Retrieved from https://www.internetworldstats.com/pacific

Livtunvanu, M. S. K. (2011). Annual development report. Government of the Republic of Vanuatu.

Papatheodorakis, I., \& Righetto, L. (n.d.). Oral Health Promotion for children in Vanuatu. Retrieved from, https://sydney.edu.au/dentistry

Schou, L. \& Locker, D. (1997). Principles of oral health promotion. Community oral health. Oxford, London: Wright.

Steel, K. D. (n.d.). Fruit of the Pacific. Retrieved from http://www.fruitofthepacific.org

Steel, K. D. (2013). Yu Me Gat Wan Big Fella Smile. Retrieved from https://www.youtube.com 
Underwood, B., Birdsall, J., \& Kay, E. (2015). The use of a mobile app to motivate evidence-based oral hygiene behaviour. British Dental Journal, 4, 1 - 7. doi: $10.1038 /$ sj.bdj.2015.660

Watt, R. G., Harnett, R. D., Fuller, S. S., Kay, E., Morgan, A., Munday, P., Nowjack - Raymer, R., \& Treasure, E. T. (2006). Evaluating oral health promotion: Need for quality outcome measures. Community Dentistry and Oral Epidemiology, 34, 11 - 17. doi: 10.1111/j.1600-0528.2006.00257.x

Willie, G. (2017). Promoting oral health in education. Vanuatu Daily Post. Retrieved from http://dailypost.vu/news/

Willie, R. (2018). Kasific promises affordable, higher speed internet in islands. Vanuatu Daily Post. Retrieved from http://dailypost.vu/news

World Bank. (2016). World development report 2016: Digital Dividends. Retrieved from http://www.worldbank.org

World Health Organisation. (2003). The world oral health report: Continuous improvement of oral health in the $21^{\text {st }}$ century - the approach of the WHO global oral health programme.

World Health Organisation. (2007). Meeting of ministers of health for the Pacific Island countries. Port Vila, Vanuatu.

World Health Organisation. (2012). Vanuatu health service delivery profile 2012. Retrieved from http://www.wpro.who.int/health_services

World Dental Association. (2017). VDA collaborates to implement oral health projects in Vanuatu. Retrieved from http://www.fdiworldental.org 